\title{
Clinical efficacy of oral mesalazine in Crohn's disease
}

\author{
KARLERnSt MAIER, MD, HANS-JÜRGEN FRICK, MD, ULRICH VON GAISBERG, MD, \\ THORSTEN TEUFEL, PHD, UlRICH KLOTZ, PHD
}

\begin{abstract}
A randomized controlled trial was performed to evaluate in Crohn's disease the clinical efficacy and safety of a higher dose of a new slow-release preparation of mesalazine ( $500 \mathrm{mg}$ tablets). Twenty-four patients treated with $3 \mathrm{~g}$ mesalazine/day were compared with 26 patients treated with sulfasalazine ( $3 \mathrm{~g} /$ day) and methylprednisolone (initially $40 \mathrm{mg}$ ). All patients had active Crohn's disease diagnosed by endoscopy, sonography and radiology. Patients were characterized before entry into the study and at two, four, eight and 12 weeks of treatment by activity indices according to Best and van Hees, as well as by erythrocyte sedimentation rate, thrombocyte count, Broca index and serum albumin. All clinical and laboratory parameters were well matched for the two groups of patients. During treatment with mesalazine and sulfasalazine/methylprednisolone, clinical remission could be observed in 20 of 24 patients $(83 \%)$ and 23 of 26 patients $(88 \%)$, respectively. There was nodifference between the two groups except for a slightly higher increase of the Broca index in the combined treatment group. Side effects were reported in three $(12.5 \%)$ and six $(23 \%)$ patients treated with mesalazine and sulfasalazine/methylprednisolone, respectively. In conclusion, oral mesalazine at a dose of $3 \mathrm{~g} /$ day was effective in active Crohn's disease and was well tolerated by the patients. Can J Gastroenterol 1990;4(1):13-18
\end{abstract}

Key Words: Crohn's disease, Mesalazine, Prednisolone, Sulfasalazine

\section{Efficacité clinique de la mésalazine orale dans la maladie de Crohn}

RESUME: Un essai clinique randomisé a été effectué afin d'évaluer l'innocuité et l'efficacité d'une dose élevée d'une nouvelle préparation de mésalazine à libération lente (comprimés de $500 \mathrm{mg}$ ) administrée dans la maladie de Crohn. Vingt-quatre patients traités par mésalazine $(3 \mathrm{~g} / \mathrm{jour})$ ont été comparés à 26

Department of Gastroenterology, Hospital Bad Cannstatt; and Dr Margarete Fischer-Bosch Institute of Clinical Pharmacology, Stuttgart, West Germany

Correspondence and reprints: Dr KMaier, Medizinische Klinik, Krankenhaus Bad Cannstatt, Prießnitzweg 24,D-7000 Stuttgart 50, Federal Republic of Germany. Telephone $0711 / 5205504$

Received for publication November 3, 1989. Accepted December 7, 1989
D RUG TREATMENT OF CROHN'S disease is based mainly on the results of the American Cooperative Crohn's Disease Study (1). While corticosteroids are indicated if inflammation is located in the small bowel, sulfasalazine and corticosteroids are helpful if both small and large bowel are involved; if the disease is restricted to the colon, monotherapy with sulfasalazine might be sufficient. Treatment failure of sulfasalazine in inflammatory processes of the small bowel is due to the fact that the active moiety of sulfasalazine - 5-aminosalicylate (mesalazine) - is not available there, because it is generated from its prodrug by reductive bacterial cleavage of the azobond in the colon (2-4).

The direct application of mesalazine appears to be advantageous especially, therefore, if its low incidence of side effects (compared with sulfasalazine) is considered (5). Likewise, higher doses of mesalazine might be used, since the dose-dependent toxic potential of sulfapyridine has been eliminated $(6,7)$. These perspectives initiated the development of a $500 \mathrm{mg}$ mesalazine tablet with a controlled release mechanism.

With this preparation a randomized controlled trial in patients with 
patients recevant de la sulfasalazine ( $3 \mathrm{~g} /$ jour) et de la méthylprednisolone (initialement $40 \mathrm{mg}$ ). Tous les patients souffraient de maladie de Crohn évolutive diagnostiquée par endoscopie, échographie et radiologie. Les patients avaient auparavant été caractérisés à deux, quatre, huit et 12 semaines de traitement selon les indices d'activité de Best et de van Hees, ainsi que d'après la vitesse de sédimentation globulaire, la numération plaquettaire, l'indice de Broca et l'albumine sérique. Tous les paramètres cliniques et de laboratoire étaient bien appariés pour les deux groupes de patients. Au cours du traitement par mésalazine et sulfasalazine/méthylprednisolone, une rémission clinique a pu être observée chez 20 patients sur $24(83 \%)$ et 23 patients sur $26(88 \%)$, respectivement. On n'a relevé aucune différence entre les deux groupes à l'exception d'une légère augmentation de l'indice de Broca dans le groupe soumis au traitement combiné. Des effets secondaires ont été rapportés chez trois $(12,5 \%)$ et six $(23 \%)$ des patients traités par mésalazine ou sulfasalazine/méthylprednisolone, respectivement. En conclusion, la mésalazine par voie orale à la dose de $3 \mathrm{~g} /$ jour est efficace dans le traitement de la maladie de Crohn évolutive et a été bien tolérée des patients.
Crohn's disease was performed to assess the clinical efficacy and safety of mesalazine at a higher dose of $3 \mathrm{~g} /$ day. For this reason the new dosage regimen was compared with the established standard regimen of sulfasalazine (3 $\mathrm{g} /$ day) and methylprednisolone (initially $40 \mathrm{mg}$ ).

\section{PATIENTS AND METHODS}

After written informed consent was obtained, 54 patients with active Crohn's disease participated in the controlled trial. Initially patients were hospitalized and, according to the severity of disease, treatment was con- tinued ambulatorily (Table 1). Patients were randomly assigned to three months oral treatment either with mesalazine $1 \mathrm{~g}$ tid (three $\mathrm{X}$ two tablets of Salofalk; Interfalk ) or sulfasalazine $1 \mathrm{~g}$ tid (three $X$ two tablets of Azulfidine; Pharmacia) and methylprednisolone (initially $40 \mathrm{mg} /$ day; weekly reduction by $4 \mathrm{mg}$ ).

Diagnoses of Crohn's disease were based on endoscopy, sonography, radiology and extensive clinical examinations. Infectious colitis was excluded by microbiological screening and testing for complement-binding reactions.

\section{TABLE 1}

\section{Demographic and clinical data (mean $\pm S D$ ) of patients with Crohn's disease before entry into the study}

\begin{tabular}{|c|c|c|}
\hline Variable & Mesalazine group & $\begin{array}{l}\text { Sulfasalazine/ } \\
\text { methylprednisolone } \\
\text { group }\end{array}$ \\
\hline Gender (male/female) & $13 / 11$ & $8 / 18$ \\
\hline Age (years) & $32+11.4$ & $30 \pm 11.6$ \\
\hline Duration of disease (years) & $7.0 \pm 5.3$ & $5.6 \pm 4.0$ \\
\hline Hospital stay (days) & $15.3 \pm 13.3$ & $24.0 \pm 10.5$ \\
\hline Broca index & $81 \pm 10.5$ & $80 \pm 14.1$ \\
\hline Best index & $264 \pm 61$ & $281 \pm 68$ \\
\hline van Hees index & $186 \pm 63$ & $204 \pm 39$ \\
\hline Erythrocyte sedimentation rate* & $35.3 \pm 21.8$ & $56.5 \pm 27.6$ \\
\hline Platelet counts $\left(\times 1000 / \mathrm{mm}^{3}\right)$ & $377 \pm 143$ & $497 \pm 139$ \\
\hline Serum albumin $(g / L)$ & $37.1 \pm 8.0$ & $35.1 \pm 5.6$ \\
\hline \multicolumn{3}{|l|}{ Location of disease } \\
\hline Colon & 5 & 3 \\
\hline lleum \& colon & 18 & 23 \\
\hline lleum \& jejunum & 1 & - \\
\hline Total number of relapses & 20 & 23 \\
\hline Chronic recurrence $(n)$ & 12 & 13 \\
\hline
\end{tabular}

- According to Westergren after $1 \mathrm{~h}$ in mm: $n$ Number of patients
Patients were excluded from the study if they met one of the following criteria: known hypersensitivity to salicylates or sulfonamides; extensive stenoses; indications for surgery; very active disease despite corticosteroid treatment; impaired liver or kidney function; or infectious colitis. None of the patients was pretreated with cortico. steroids.

Clinical efficacy was assessed by the following criteria: decline in the activity indices according to Best (8) and van Hees (9); reduction in erythrocyte sedimentation rate and platelet counts; and increase in serum albumin and body weight (Broca index). Remission was defined as a Best index score of less than 150 .

All these parameters were monitored before and after two, four, eight and 12 weeks of the randomized treatment. In addition, at those time points the following laboratory parameters were controlled: erythrocyte and leukocyte counts; hemoglobin; hematocrit; serum creatinine; sodium; potassium; prothrombin time; alanine aminotransferase; aspartate aminotransferase; gamma-glutamyl transferase; and urine status. Patients were also interviewed for side effects and co-medication (no anti-inflammatory drugs such as azathioprine or metronidazole were allowed).

Patients were educated to record on cards number of bowel movements, consistency of stool, abdominal discomfort and general health status.

Both treatment groups were compared by the unpaired two-tailed Student's $t$ test.

\section{RESULTS}

According to protocol the study was completed by 50 patients. The four drop outs were due to withdrawal of given informed consent, moving away, protocol violation and indication for surgery. Before entry into the study all the demographic and clinical data of both groups were comparable (Table 1).

Clinical remission was induced in 20 patients $(83 \%)$ of the mesalazine group and in 23 patients $(88.5 \%)$ of the sulfasalazine/corticosteroid group. The 
TABLE 2

Clinical and laboratory parameters (mean \pm SD) for assessing clinical efficacy in both treatment groups

\begin{tabular}{|c|c|c|c|c|c|}
\hline $\begin{array}{l}\text { Parameters } \\
\text { Treatment groups }\end{array}$ & Initially & 2 weeks & 4 weeks & 8 weeks & 12 weeks \\
\hline \multicolumn{6}{|l|}{ van Hees index } \\
\hline Mesalazine & $186(63)$ & $203(49)$ & $161(53)$ & $137(45)$ & $131(47)$ \\
\hline Sulfa/cortisone & 204 (39) & $196(39$ & $165(36)$ & $144(36)$ & $136(40)$ \\
\hline \multicolumn{6}{|l|}{ Best index } \\
\hline Mesalazine & $264(61)$ & $237(65)$ & $192(71)$ & $136(40)$ & $116(73)$ \\
\hline Sulfa/cortisone & $281(68)$ & $233(63)$ & $162(76)$ & $123(47)$ & $135(78)$ \\
\hline \multicolumn{6}{|l|}{ Broca index } \\
\hline Mesalazine & $81.2(10.5)$ & $82.2(11.2)$ & $81.6(8.6)$ & $83.2(8.4)$ & $83.8(7.0)$ \\
\hline Sulfa/cortisone & $80.0(14.1)$ & $79.0(12.4)$ & $81.9(12.2)$ & $80.8(10.7)$ & $84.3(12.2)$ \\
\hline \multicolumn{6}{|l|}{ ESR } \\
\hline Mesalazine & $35(22)$ & $37(23)$ & $30(25)$ & $23(22)$ & $21(21)$ \\
\hline Sulfa/cortisone & $57(28)$ & $50(26)$ & $34(25)$ & $26(24)$ & $21(17)$ \\
\hline \multicolumn{6}{|l|}{ Platelets $\left(\times 1000 / \mathrm{mm}^{3}\right)$} \\
\hline Mesalazine & $377(143)$ & $454(127)$ & $388(134)$ & $354(103)$ & $334(106)$ \\
\hline Sulfa/cortisone & 497 (139) & $480(130)$ & $423(121)$ & $389(103)$ & $378(113)$ \\
\hline \multicolumn{6}{|l|}{ Serum albumin $(\mathrm{g} / \mathrm{L}$ ) } \\
\hline Mesalazine & $37.1(8.0)$ & $34.0(5.3)$ & $37.9(6.9)$ & $40.2(5.9)$ & $41.2(6.6)$ \\
\hline Sulfa/cortisone & $35.1(5.6)$ & $34.2(5.0)$ & $37.3(4.9)$ & $39.2(4.9)$ & $40.2(5.3)$ \\
\hline
\end{tabular}

ESREnthrocyte sedimentation rate: Sulfa Sulfasalazine

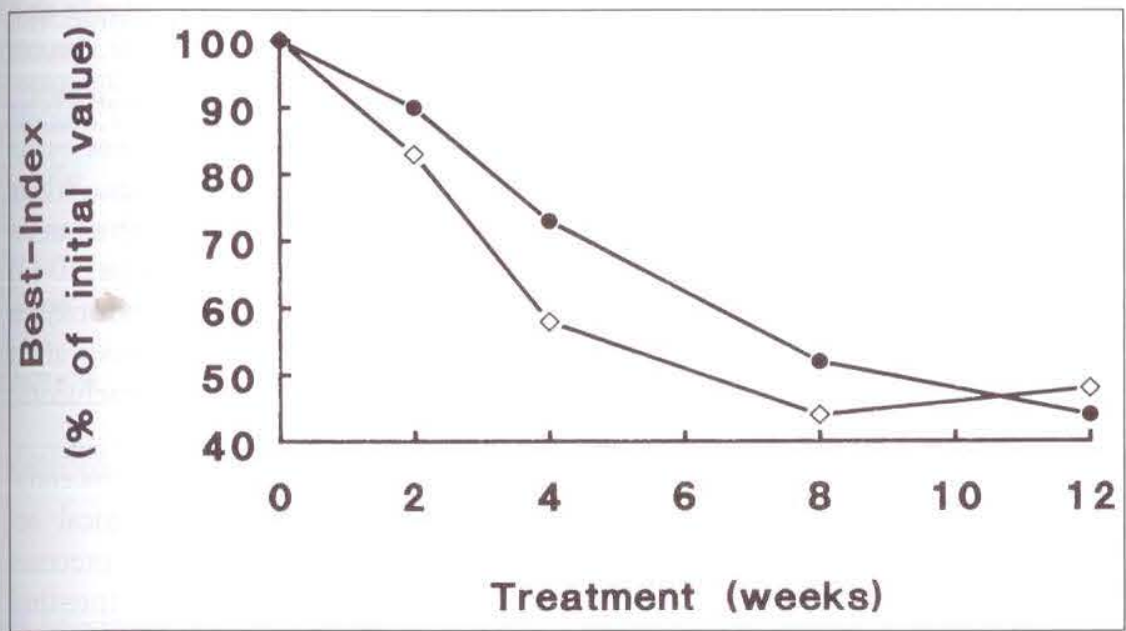

Figure 1) Averaged time-dependent decrease in the relative Best activity index in patients with Crohn's disease treated with either mesalazine $1 \mathrm{~g}$ tid (closed circles) or sulfasalazine $1 \mathrm{~g}$ tid and methylprednisolone (diamonds)

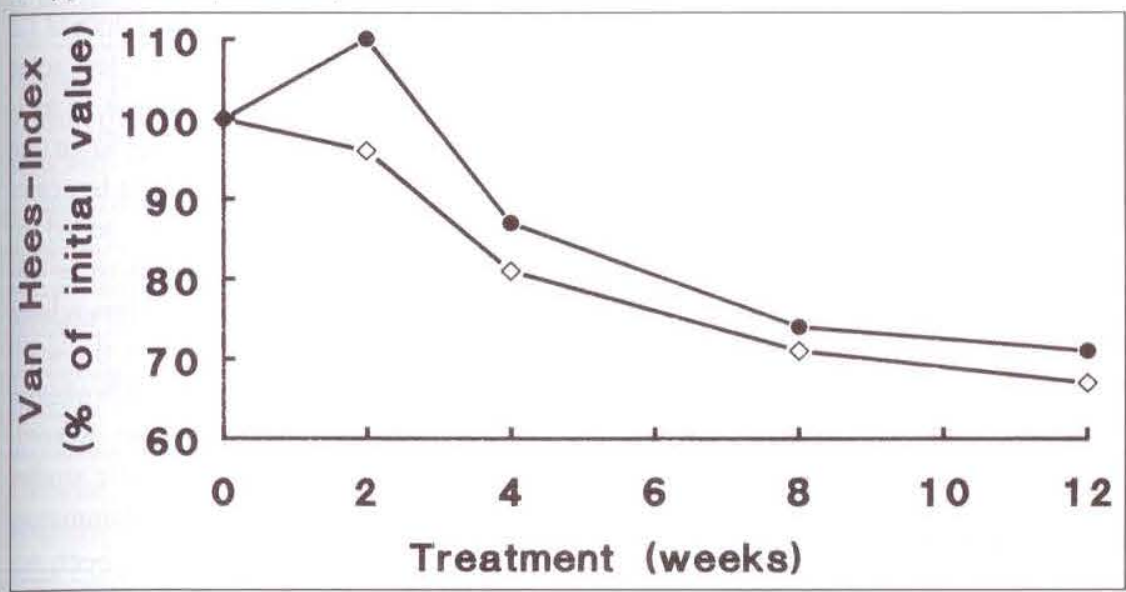

Figure 2) Averaged time-dependent decrease in the relative van Hees activity index in patients with Crohn's disease treated with either mesalazine $1 \mathrm{~g}$ tid (closed circles) or sulfasalazine $1 \mathrm{~g}$ tid and methylprednisolone (diamonds) mean values $( \pm S D)$ for the various clinical and laboratory criteria are summarized in Table 2. In both groups there was an almost parallel decline in the two activity indices (Figures 1,2), erythrocyte sedimentation rate (Figure 3 ) and platelet count (Figure 4), as well as an increase in serum albumin (Figure 5) and body weight (Figure 6) during the treatment period of 12 weeks.

The observed side effects are listed in Table 3. The absolute and relative numbers of adverse events were higher in the sulfasalazine/corticosteroid group $(n=6 ; 23 \%)$ than in the mesalazine-treated patients $(n=3$; $12.5 \%)$. In two patients sulfasalazine had to be withdrawn and in one patient dose was reduced because of increases in hepatic marker enzymes. Mesalazine had to be discontinued in one patient because of reversible increases in transaminases; hair loss and acne improved despite continuation of mesalazine. Otherwise, none of the monitored laboratory values (eg, serum creatinine, electrolytes, transaminases, prothrombin time, urine status) was affected by the drug treatment.

\section{DISCUSSION}

This comparative study clearly indicates that oral mesalazine at a dose of 3 $\mathrm{g} /$ day is effective in the treatment of active Crohn's disease. According to commonly applied activity indices and laboratory parameters assessing the severity of the inflammatory processes, the mesalazine-induced remission rate with the new dose regimen ( $1 \mathrm{~g}$ tid) was comparable to the established treatment with sulfasalazine and corticosteroids (Table 2). In addition, mesalazine was superior to the combined standard treatment in terms of side effects (Table 3 ).

During the randomized controlled trial one minor difference was observed between both groups (Table 2). At the end of the 12 week treatment period patients on combined treatment gained slightly more body weight $(\mathrm{P}=0.024)$ according to the Broca index. This effect could also have been caused by the water retaining effect of the co-administered methylprednisolone.

The time profiles in the changes of 


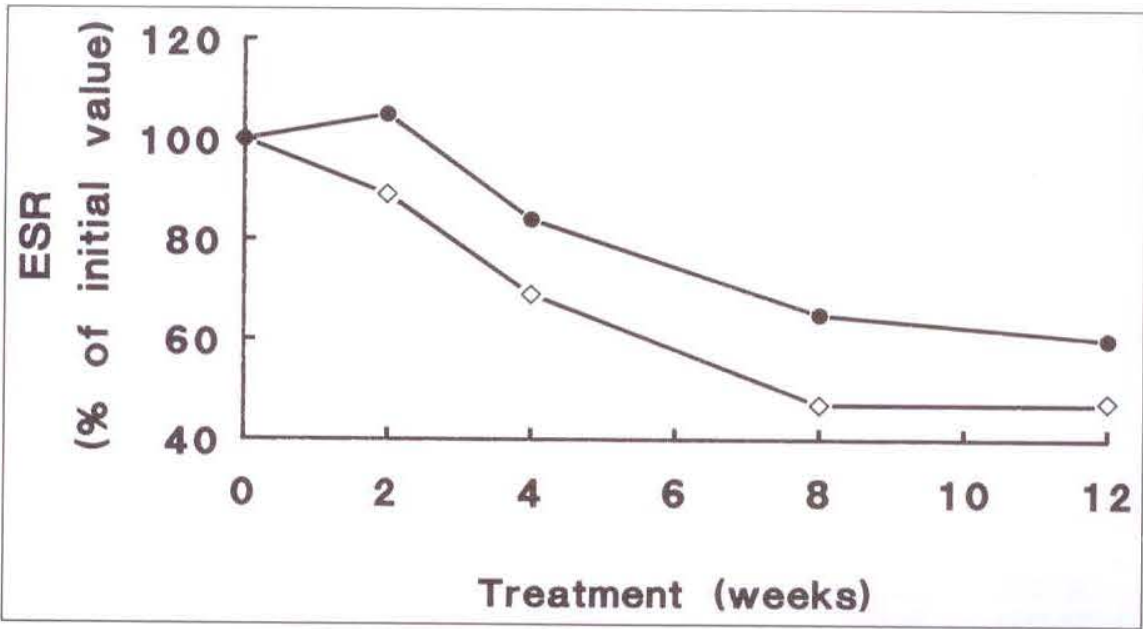

Figure 3) Averaged time-dependent decrease in the relative erythrocyte sedimentation rate (ESR) in patients with Crohn's disease treated either with mesalazine $1 \mathrm{~g}$ tid (closed circles) or with sulfasalazine $1 \mathrm{~g}$ tid and methylprednisolone (diamonds)

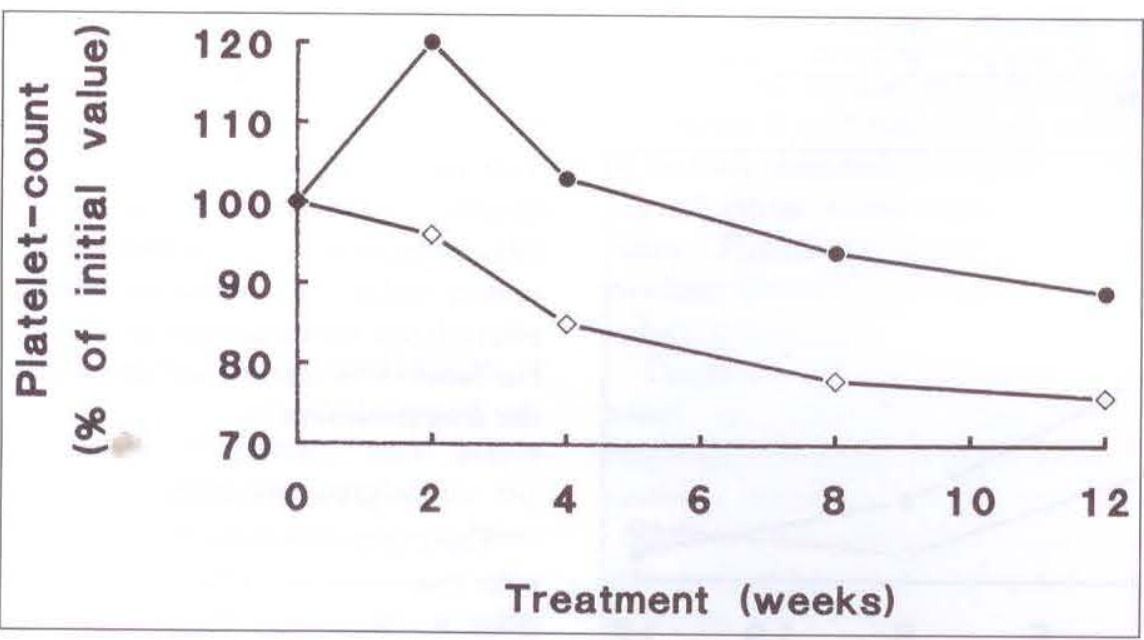

Figure 4) Averaged time-dependent decrease in the relative platelet counts in patients with Crohn's disease treated either with mesalazine $1 \mathrm{~g}$ tid (closed circles) or with sulfasalazine $1 \mathrm{~g}$ tid and methylprednisolone (diamonds)

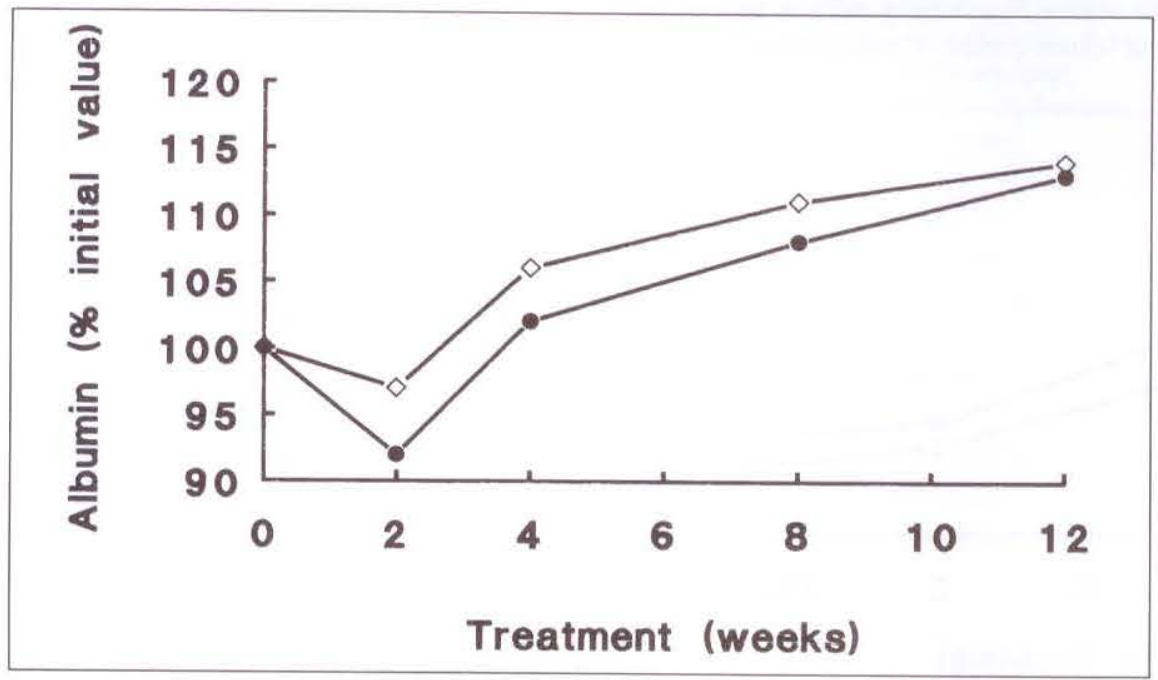

Figure 5) Averaged time-dependent increase in the relative serum albumin values in patients with Crohn's disease treated either with mesalazine $1 \mathrm{~g}$ tid (closed circles) or with sulfasalazine $1 \mathrm{~g}$ tid and methylprednisolone (diamonds) the various clinical parameters (Figures 1-6) indicated that patients with Crohn's disease responded somewhat earlier to sulfasalazine/corticosteroids than to monotherapy with mesalazine. This marginal difference appears be due to the initial dosing with $40 \mathrm{mg}$ methylprednisolone. Nevertheless oral mesalazine at the higher dose of $3 \mathrm{~g} /$ day offers an effective alternative for patients with active Crohn's disease since its remission rate of $83 \%$ is com. parable to standard treatment. Whether an even higher and/or faster remission rate could be achieved by combining mesalazine with corticosteroids remains to be evaluated. However, for the four nonresponders to mesalazine, if $100 \mathrm{mg}$ methylpred. nisolone were subsequently added to their drug regimen, remission was induced within four weeks. No side effects were observed during this combined treatment.

These apparently additive effects are most likely due to the different modes of action of the two drugs. Where mesalazine probably acts both as an inhibitor of leukotriene synthesis (10-12) and a potent scavenger of toxic oxygen radicals $(13,14)$, corticosteroids affect the initial liberation of arachidonic acid from phospholipids.

Since mesalazine's dose/concentration-dependent pharmacological actions and the inflammatory processes both occur within the intestinal mucous cells, it is important that sufficient active drug is available at these sites of inflammation. Apparently the present mesalazine standard dose of 1.5 $\mathrm{g} /$ day might be too low for some patients with Crohn's disease as indicated by a Danish study (15) or the authors' first experience (in a few cases corticosteroids had to be added to mesalazine) (16). It appears to be important that mesalazine tablets release enough active ingredients in the small bowel which in more than $75 \%$ of cases is inflamed in Crohn's disease. Accord. ing to earlier pharmacokinetic studies in patients with chronic inflammatory bowel disease this goal has been accomplished by the special galenic for. mulation of the mesalazine preparation used (5). Since the absorbed amounts 


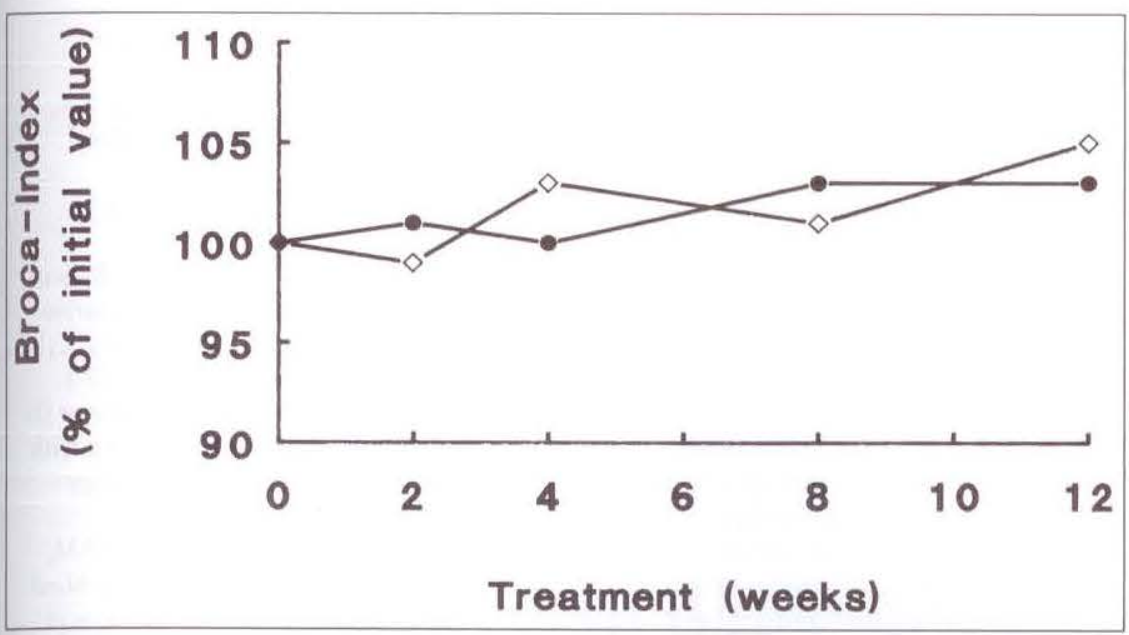

Figure 6) Averaged time-dependent increase in the relative Broca index in patients with Crohn's disease treated either with mesalazine $1 \mathrm{~g}$ tid (closed circles) or with sulfasalazine $1 \mathrm{~g}$ tid and methylprednisolone (diamonds)

TABLE 3

Observed adverse events

\begin{tabular}{|c|c|c|}
\hline Side effects & Number of patients & Comments \\
\hline $\begin{array}{l}\text { Nausea, vomiting, } \\
\text { epigastric pain }\end{array}$ & 3 & $\begin{array}{l}\text { Dose of sulfasalazine kept } \\
\text { constant }\end{array}$ \\
\hline $\begin{array}{l}\text { Nausea, vomiting, } \\
\text { epigastric pain }\end{array}$ & 1 & Sulfasalazine withdrawn \\
\hline Exantheme & 1 & Sulfasalazine withdrawn \\
\hline Increase of transaminases & 1 & $\begin{array}{l}\text { Dose of sulfasalazine } \\
\text { reduced }\end{array}$ \\
\hline Acne & 1 & $\begin{array}{l}\text { Dose of mesalazine kept } \\
\text { constant }\end{array}$ \\
\hline Hair loss & 1 & $\begin{array}{l}\text { Dose of mesalazine kept } \\
\text { constant }\end{array}$ \\
\hline Increase of transaminases & 1 & Mesalazine withdrawn \\
\hline
\end{tabular}

of mesalazine are immediately acetylated by the intestinal mucosa and the liver $(17,18)$, only low concentrations of unchanged mesalazine are found in the circulating blood $(5,18)$. This extensive presystemic elimination can explain the low incidence of side effects seen with mesalazine.

Intestinal transit time will probably affect how much of a mesalazine dose will actually reach its target. Therefore, it could be anticipated that substances inhibiting motility such as loperamide could be of additional value in cases of accelerated gastrointestinal passage. Likewise, co-administration of cholestyramine which binds bile acid might reduce diarrhea.

So far mesalazine (in the form of suppositories, enemas and tablets) has proven its clinical efficacy for inducing and maintaining remission in numerous patients with ulcerative colitis $(2,19-27)$. From the present study it is apparent that a special oral form of mesalazine at a dose of $3 \mathrm{~g} /$ day is also an effective and safe treatment for patients with Crohn's disease. As its clinical efficacy is comparable to standard treatment and since it is even better tolerated, mesalazine may be considered the drug of choice in active Crohn's disease of moderate severity.

\section{REFERENCES}

1. Summers RW, Switz DM, Sessions JT Jr, et al. National Cooperative Crohn's Disease Study (NCCDS): Results of drug treatment. Gastroenterology 1979;77:847-69.

2. Azad-Kahn AK, Piris J, Truelove SC. An experiment to determine the active therapeutic moiety of sulfasalazine.
Lancet 1977;ii:892-5

3. van Hees PAM, Bakker JH, van Tongeren JHM. Effect of sulfapyridine, 5 aminosalicylic acid and placebo in patients with idiopathic proctitis: A study to determine the active therapeutic moiety of sulfasalazine. Gut 1980;21:632-5.

4. Klotz U, Maier K, Fischer C, Heinkel K. Therapeutic efficacy of sulfasalazine and its metabolites in patients with ulcerative colitis and Crohn's disease.

N Engl J Med 1980;303:1499-502.

5. Klotz U, Maier K. Pharmacology and pharmacokinetics of 5-aminosalicylic acid. Dig Dis Sci 1987;32:46S. $50 \mathrm{~S}$.

6. Das KM, Eastwood MA, McManus JP. Sircus W. Adverse reactions during salicylazosulfapyridine therapy and the relation with drug metabolism and acetylator phenotype. N Engl J Med 1973;289:491-5.

7. Peppercorn MA. Sulfasalazine: Pharmacology, clinical use, toxicity and related new drug development. Ann Intern Med 1984;3:377-86.

8. Best WR, Becktel JM, Singleton JW, Kern F. Development of a Crohn's disease activity index. National cooperative Crohn's disease study. Gastroenterology 1976;70:439-44.

9. van Hees PAM, van Elteren PH, van Lier HJJ, van Tongeren JHM. An index of inflammatory activity in patients with Crohn's disease. Gut 1980;21:279-86.

10. Peskar BM, Dreyling KW, Peskar BA, May B, Goebell H. Enhanced formation of sulfidopeptide-leukotrienes in ulcerative colitis and Crohn's disease: Inhibition by sulfasalazine and 5-aminosalicylic acid. Agents Actions 1986;18:381-3.

11. Sharon P, Stenson WF. Enhanced synthesis of leukotriene $\mathrm{B}_{4}$ by colonic mucosa in inflammatory bowel disease. Gastroenterology 1984;86:453-60.

12. Stenson WF, Lobos E. Sulfasalazine inhibits the synthesis of chemotactic lipids by neutrophils. J Clin Invest 1982;69:494-7.

13. Kvietys PR, Smith SM, Gresham MT, Manci EA. 5-Aminosalicylic acid protects against ischemia/reperfusioninduced gastric bleeding in the rat. Gastroenterology 1988;94:733-8.

14. Miyachi Y, Yoshioka A, Imamura S, Niwa Y. Effect of sulphasalazine and its metabolites on the generation of reactive oxygen species. Gut 1987;28:190-5.

15. Rasmussen SN, Lauritsen K, TageJensen U, et al. 5-A minosalicylic acid in the treatment of Crohn's disease. A 16-week double-blind, controlled, multicentre study with Pentasa. Scand J 
Gastroenterol 1987;22:877-83.

16. Maier K, Frühmorgen P, Bode JCH, et al. Erfolgreiche Akutbehandlung chronisch entzündlicher

Darmerkrankungen mit oraler-5. aminosalicylsäure. Dtsch Med Wochenschr 1985;10:363-8.

17. Allgayer $\mathrm{H}$, Ahnfelt NO, Kruis W, et al. Colonic acetylation of 5-aminosalicylic acid in inflammatory bowel disease. Gastroenterology 1989;97:3841.

18. Klotz U, Laver P, Nehlsen B, Goebell H. Delivery of mesalazine (5-ASA) to the distal ileal lumen by an oral slow release preparation. Eur J Clin Pharmacol 1989;36:A95.

19. Dew MJ, Highes $P$, Harris AD, Williams G, Evans BK, Rhodes J. Maintenance of remission with oral preparation of 5-aminosalicylic acid doses by mouth. Br Med J
1983;285:1012-4.

20. Habal FM, Greenberg GR. Treatment of ulcerative colitis with oral 5-aminosalicylic acid including patients with adverse reactions to sulfasalazine. Am J Gastroenterol 1988;83:15-9.

21. Mulder CJJ, Tytgat GNJ, Waterman IT, et al. Double-blind comparison of slow-release 5-aminosalicylate and sulfasalazine in remission maintenance in ulcerative colitis. Gastroenterology 1988;95:1449-53.

22. Riley SA, Mani V, Goodman MJ, Herd ME, Dutt S, Turnberg LA.

Comparison of delayed release 5 . aminosalicylic acid (mesalazine) and sulphasalazine in treatment of mild to moderate ulcerative colitis relapse. Gut 1983;29:669-74.

23. Schroeder KW, Tremaine WJ, Ilstrup DM. Coated oral 5-aminosalicylic acid therapy for mildly to moderately active ulcerative colitis. N Engl J Med 1987;317:1625-9.

24. Barber GB, Lee DE, Antonioli DA, Peppercorn MA. Refractory distal ulcerative colitis responsive to 5-aminosalicylate enemas. Am J Gastroenterol 1985;80:1-4.

25. Campieri M, Lanfranchi GA, Bazzocchi $\mathrm{G}$, et al. Treatment of ulcerative colitis with high dose 5-aminosalicylic acid enemas. Lancet 1981;ii:270-1.

26. Hanauer SB, Schultz PA, Kirshner JB. Treatment of refractory proctitis with 5-ASA enemas. Gastroenterology 1985;88:1412.

27. van Hogezand RA, van Hees PAM, van Gorp JPWM, et al. Double-blind comparison of 5-aminosalicylic acid and acetyl-5-aminosalicylic acid suppositories in patients with idiopathic proctitis. Ali Pharmacol Ther 1988;2:33-40. 


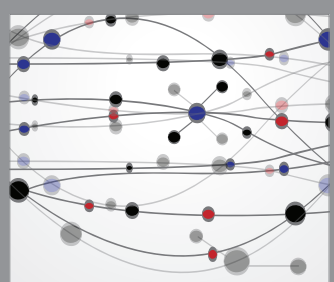

The Scientific World Journal
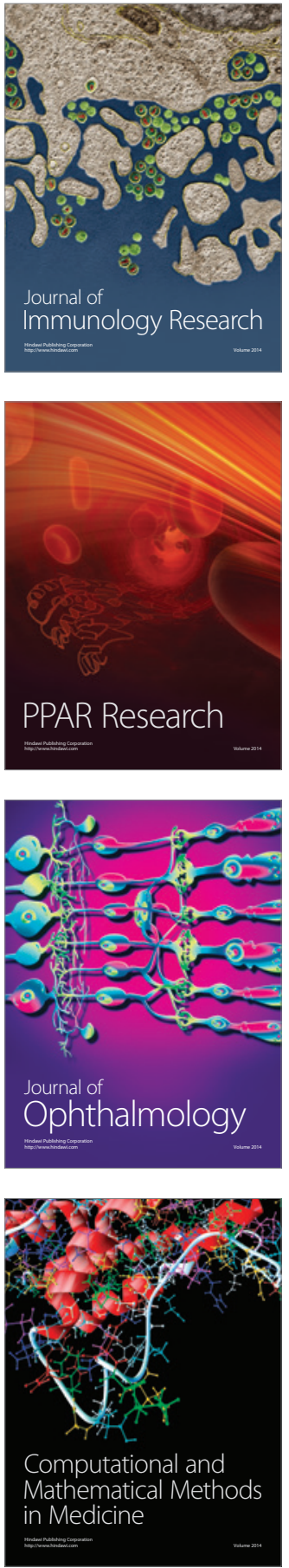

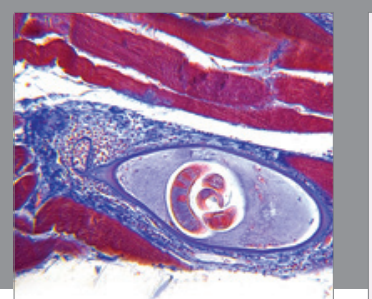

Gastroenterology Research and Practice

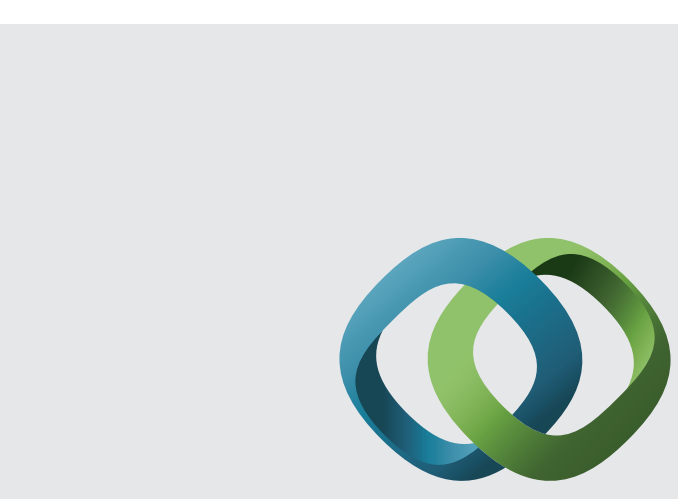

\section{Hindawi}

Submit your manuscripts at

http://www.hindawi.com
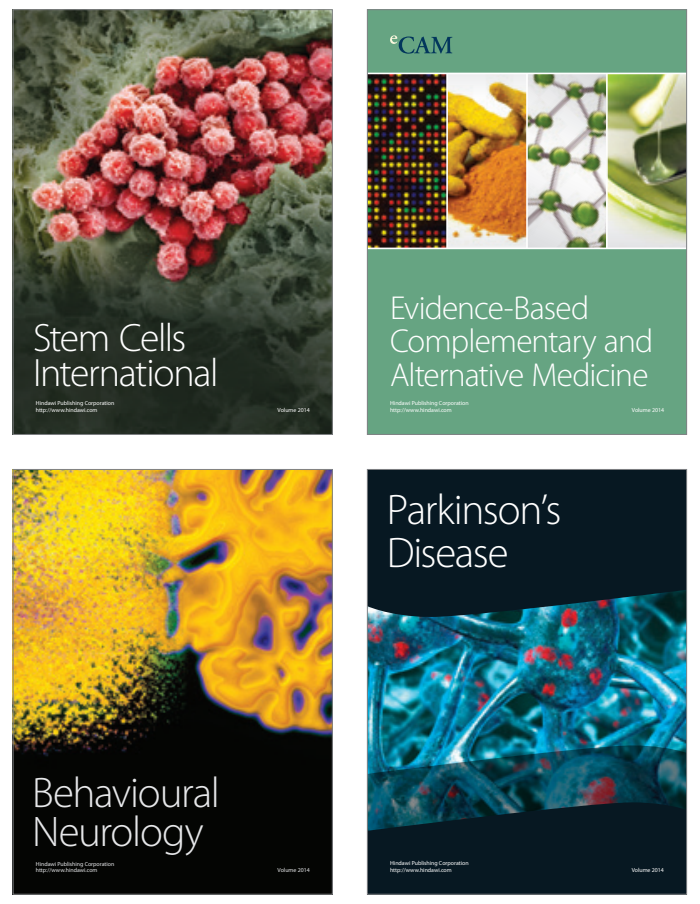
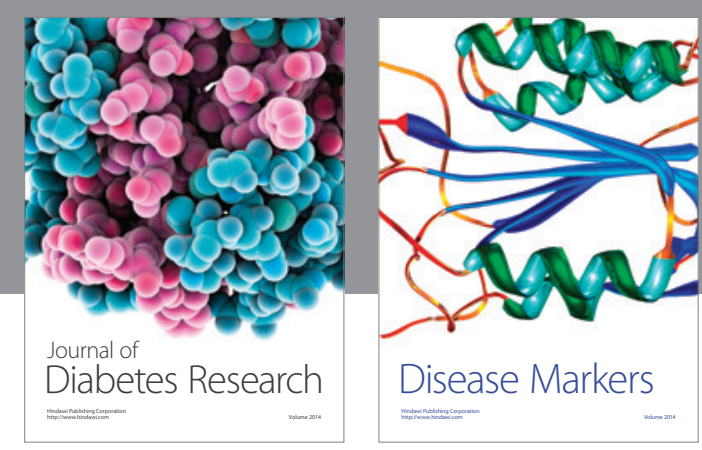

Disease Markers
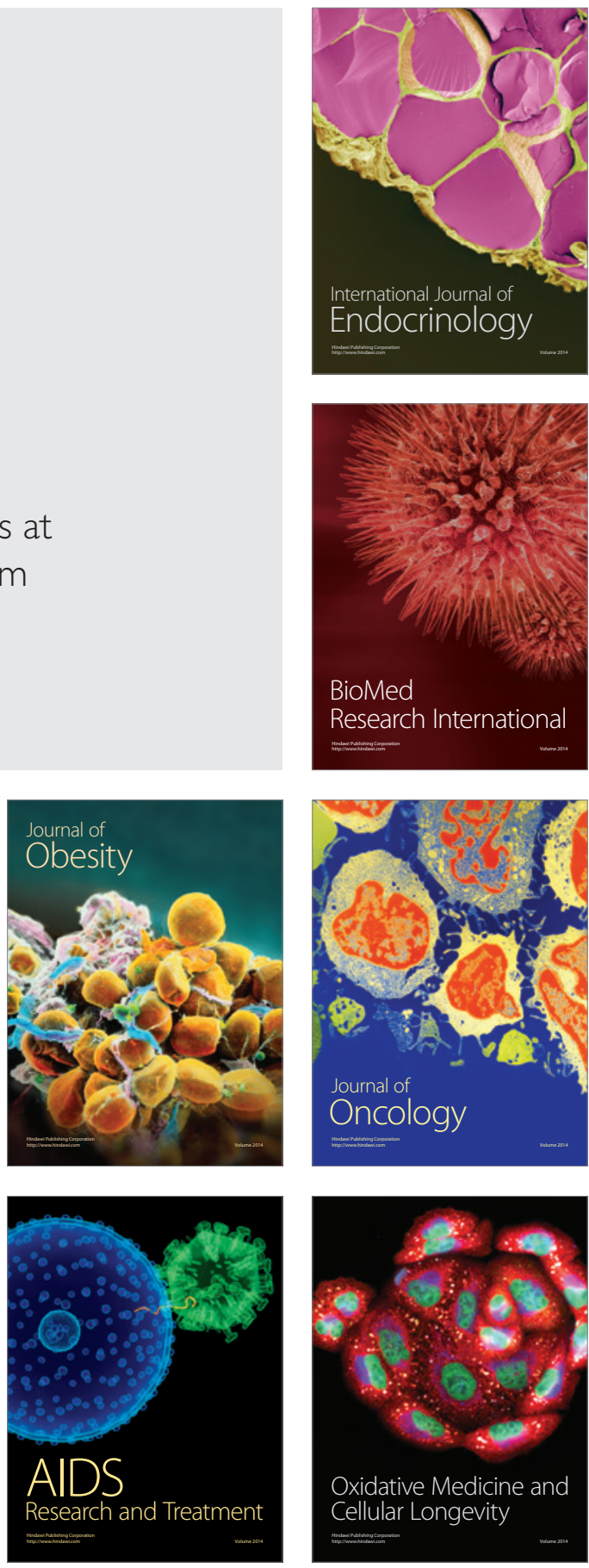